\title{
Magneto-controlled potentiometric assay for E. coli based on cleavage of peptide by outer-membrane protease $\mathrm{T}$
}

\author{
Han Zhang ${ }^{\mathrm{a}, \mathrm{d}}$, Junsong Mou ${ }^{\mathrm{a}, \mathrm{d}}$, Jiawang Ding ${ }^{\mathrm{a}, \mathrm{b}, \mathrm{c}, *}$, Wei Qin ${ }^{\mathrm{a}, \mathrm{b}, \mathrm{c}}$ \\ ${ }^{a}$ CAS Key Laboratory of Coastal Environmental Processes and Ecological Remediation, Yantai Institute of Coastal Zone Research (YIC), Chinese Academy of \\ Sciences(CAS); Shandong Key Laboratory of Coastal Environmental Processes, YICCAS, Yantai, Shandong 264003, P R China \\ ${ }^{\mathrm{b}}$ Laboratory for Marine Biology and Biotechnology, Pilot National Laboratory for Marine Science and Technology (Qingdao), Shandong 266237, P R China \\ ${ }^{c}$ Center for Ocean Mega-Science, Chinese Academy of Sciences, Qingdao, Shandong, 266071, P R China \\ ${ }^{\mathrm{d}}$ University of Chinese Academy of Sciences, Beijing 100049, P R China
}

\section{A R T I C L E I N F O}

\section{Article history:}

Received 2 February 2021

Revised 30 March 2021

Accepted 11 April 2021

Available online 21 April 2021

\section{Keywords:}

Potentiometric

Peptide

Magnetic field

Bacteria

Outer-membrane protease $\mathrm{T}$

\begin{abstract}
A B S T R A C T
Rapid, sensitive and reliable Escherichia coli (E. coli) detection and identification are critically important to protect public health. Here, we describe a magneto-controlled potentiometric assay for specific detection of $E$. coli cells by making use of the E. coli outer-membrane protease T (OmpT). OmpT is an endopeptidase that specifically cleaves peptide at dibasic sites. A rationally designed peptide serving as both OmpT substrate and potentiometric signal reporter was immobilized on magnetic beads. The rapid accumulation and extraction of peptide-functionalized magnetic beads on a polymeric membrane doped with an ion exchanger can be achieved using a magnetic force. The magnetic-field-assisted extraction of the peptide into the polymeric membrane ion-sensitive sensor, as confirmed by Fourier transform infrared spectroscopy and X-ray photoelectron spectroscopy, can lead to a rapid, stable and reproducible potential change. OmpT is capable of cleaving the positively charged peptide on the magnetic beads, thus resulting in charge density change. The change in charge density and subsequently the potential change can be readily detected and used for quantification of E. coli at levels down to $5.0 \times 10^{3} \mathrm{CFU} \mathrm{mL}^{-1}$. This work provides a versatile, rapid and reliable potentiometric method for $E$. coli detection.
\end{abstract}

(c) 2021 Elsevier Ltd. All rights reserved.

\section{Introduction}

Escherichia coli (E. coli) is a gram-negative bacillus and known to pose a serious threat to public health. Some of the E. coli strains can cause various intestinal or extraintestinal infections, severe foodborne diseases and even lead to death. [1] Currently, E. coli has been used as an indicator for routine analysis of the possible existence of pathogenic microbial species in contaminated water and food sources. [2-4] The standards set by the World Health Organization for drinking water and wastewater are 0 and $1000 \mathrm{CFU} 100 \mathrm{~mL}^{-1}$, respectively. [5] For the detection of E. coli, traditional plate counting method is reliable but labor-intensive and time-consuming. [6] In order to meet the growing demand for sensitive and rapid bacteria detection, various technologies have been developed, such as enzyme-linked immune sorbent assay, [7] polymerase chain reaction, [8] cell counting via flow cytometry, [9] quartz crystal microbalance, [10] nanosensor [11] and so

\footnotetext{
* Corresponding author.

E-mail address: jwding@yic.ac.cn (J. Ding).
}

on. While these detection methods are accurate and sensitive, each technique still has its own limitations. Therefore, the development of simple, sensitive, selective and reliable assays for $E$. coli detection is still drawing a fair amount of attention.

Potentiometric polymeric membrane sensors show advantages of small size, rapid response, low cost and resistance to color and turbidity interferences and are deemed as a promising tool for ion sensing. [12-16] In recent years, with the introduction of receptors such as aptamers, antibodies and molecularly imprinted polymers, potentiometric sensors provide a new means for the detection of bacterial cells. [17] Among these bioreceptors, peptide with unique features such as good affinity, high stability and versatile sequences is an ideal biorecognition element for potentiometric sensing of bacteria. [18,19] Recently, we designed a magnetocontrolled extraction of peptide-modified magnetic beads onto/into polymeric membranes for the detection of bacteria. [20] The cooperative ion-pairing interactions between lipophilic ion-exchanger species in the membrane and the magnetic-field-assisted extraction of peptide lead to an non-equilibrium electromotive force response in a similar way to the polyion sensor. [21] Moreover, magnetic beads could eliminate the background interferences and al- 
Table 1

Peptide designed for E. coli J96 in this work.

\begin{tabular}{lll}
\hline Peptide & Sequence $^{\mathrm{a}}$ & Charge number $^{\mathrm{b}}$ \\
\hline Peptide-1R & biotin-LLLR & +1 \\
Peptide-3R & biotin-LLLRRR & +3 \\
Peptide-5R & biotin-LLLRRRRR & +5 \\
Peptide-9R & biotin-LLLRRRRRRRRR & +9 \\
Peptide-PR & biotin-LLLRRPRPRPRPR & +6 \\
\hline
\end{tabular}

${ }^{\text {a }} \mathrm{L}, \mathrm{R}$, and $\mathrm{P}$ are glycine, arginine and proline, respectively.

b Charge numbers were calculated by the NovoPro Bioscience Inc. (Shanghai, China).

low for sensitive and rapid detection of low colony-forming unit bacteria. Although the disposable potentiometric sensor array can achieve multiple bacteria classification and identification in a rapid way, there is significant room for the improvement of selectivity.

Herein, we report on a label-free potentiometric assay for specific detection of $E$. coli based on cleavage of peptide by outermembrane protease $\mathrm{T}(\mathrm{OmpT})$. OmpT is a proteolytic enzyme on the outer membrane of E. coli and acts as the key virulence factor of $E$. coli degrading host immune responsibility-related proteins, cell matrix proteins, and interfering with host hemostatic function. [22] OmpT is known to cleave short peptides preferentially at dibasic sites [such as -R (arginine) -R-, -K (lysine) -K-, -K-R-, and -R-K-]. [23-25] Its pyrolysis efficiency was comparable to that of watersoluble proteases such as chymotrypsin. [26] In this work, taking advantage of the charge originated from the zwitterionic and amphipathic properties of peptide, a peptide serving as both OmpT substrate and potentiometric signal reporter was designed and immobilized on magnetic beads. Magnetic field-driven extraction of peptide-modified magnetic beads onto/into polymeric membranes ion-sensitive sensor leads to a rapid, stable and reproducible potential response. OmpT on E. coli is capable of cleaving the peptide on the magnetic beads, which can result in a potential change and be used for detection of $E$. coli. It will be shown that $E$. coli can be selectively detected by the proposed magneto-controlled potentiometric assay.

\section{Experimental section}

\subsection{Materials}

Dinonylnaphthalenesulfonate (DNNS), high molecular weight poly(vinyl chloride) (PVC), 2-nitrophenyl octyl ether (o-NPOE) and tetradodecylammonium tetrakis (4-chlorophenyl)borate (ETH 500) were purchased from Sigma-Aldrich. Streptavidin-modified magnetic beads (MBs, $1 \mu \mathrm{m}, 10 \mathrm{mg} \mathrm{mL}^{-1}$ ) were bought from BioMag Scientific Inc. (Wuxi, China). All the peptides (Table 1) were synthesized by GL Biochem Ltd. (Shanghai, China). E. coli BL21 and E. coli J96 ATCC ${ }^{7} 700336^{\mathrm{TM}}$ were purchased from Bluefbio. (Shanghai, China). Staphylococcus aureus was purchased from BIOBW Biotechnology Co., Ltd. (Beijing, China). The number of colonyforming units per $\mathrm{mL}$ (CFU $\mathrm{mL}^{-1}$ ) was determined by the surface plate counting method. Materials for bacteria culture were purchased from Qingdao Hopebio-Technology Co., Ltd (Qingdao, China). Tetrahydrofuran and other materials were obtained from Sinopharm Chemical Reagent Co., Ltd. Coastal seawater samples were collected from coastal area (Yantai, China, $121.60^{\circ} \mathrm{E}, 37.38^{\circ} \mathrm{N}$ ). Seawater certified reference material for trace metals (NASS-6) was purchased from National Research Council Canada. Aqueous solutions were prepared with freshly deionized water $(18.2 \mathrm{M} \Omega . \mathrm{cm}$ specific resistance) obtained with a Synergy ${ }^{\circledR}$ UV water purification system.

\subsection{Electrodes and membranes}

The screen-printed ceramic electrodes with carbon ink as indicator electrodes substrate and $\mathrm{Ag} / \mathrm{AgCl}$ ink as reference electrodes substrate were manufactured by Shenzhen Xinci Technology Co. LTD (Shenzhen, China). It should be noted that the thickness of carbon layers may have an influence on the potentiometric responses of the MBs under same magnetic field. The membrane cocktail solution containing 49 wt\% PVC, 49 wt\% o-NPOE, 1 wt\% DNNS, 1 wt\% ETH 500 was prepared as described in previous research. [20,27] For the fabrication of the electrodes, $10 \mu \mathrm{L}$ membrane cocktail was drop-casted on the indicator electrodes. The prepared electrodes were finally left to dry. The thickness of the sensing membrane was approximately $50 \mu \mathrm{m}$. Membrane thicknesses were visually measured with a CX31-32C02 Olympus microscope (Tokyo, Japan).

\subsection{Potentiometric measurement}

Potentiometric measurements were carried out using a Model PXSJ-226 digital ion analyzer (Shanghai INESA \& Scientific Instrument CO. LTD, China) at room temperature in a custom-built cell with $1.0 \mathrm{~mL}$ phosphate buffered solutions (PBS, pH 7.4) containing $1.0 \mathrm{mM} \mathrm{NaCl}$. The custom-built cell $(40 \mathrm{~mm} \times 40 \mathrm{~mm} \times 23 \mathrm{~mm})$ was made of polytetrafluoroethylene with the inner dimensions of $20 \mathrm{~mm} \times 18 \mathrm{~mm} \times 15 \mathrm{~mm}$. The screen-printed ion-sensitive electrode $(40 \mathrm{~mm} \times 18 \mathrm{~mm} \times 0.635 \mathrm{~mm})$ was placed on the bottom of the cell (Fig. S1 in the supporting information). The magnetic field was controlled with the number of the applied magnets (surface magnetic field strength, 750 gausses; magnetic force, $3 \mathrm{~kg}$; size, $40 \mathrm{~mm} \times 20 \mathrm{~mm} \times 2 \mathrm{~mm})$.

\subsection{Characterization of the polymeric membrane}

The appearances of membranes without and with addition of MBs-peptide (magnetic beads modified with the peptide) under magnetic force were measured by field-emission scanning electron microscope (FESEM, S-4800, Hitachi, Japan). The elemental compositions of these membranes were analyzed by X-ray photoelectron spectroscopy (XPS, ESCALAB $\mathrm{Xi}^{+}$, Thermo Scientific, Japan). Fourier Transform Infrared Spectrometer (Nicolet iS50, Thermo Fisher, USA) was used to confirm the extraction of MBs-peptide into the polymeric membrane. Zeta potential measurements were carried out by Malvern Zetasizer Nano-ZS90 (ZEN3590, Malvern, UK). The molecular dynamics simulation was carried out using Discovery Studio 3.0 (Accelrys Software Inc.) as described in previous research. [28]

\subsection{E. coli detection}

The streptavidin-modified magnetic beads (MBs, $10 \mathrm{mg} \mathrm{mL}^{-1}$ ) were incubated with the biotin-labelled peptide $\left(1.0 \times 10^{-5} \mathrm{M}\right)$ at the ratio of $1: 9$ for $30 \mathrm{~min}$. After washing with PBS and magnetic separation, MBs-peptide was obtained. For detection of E. coli, MBs-peptide was incubated with $E$. coli at different concentrations for $1 \mathrm{~h}$ at $37{ }^{\circ} \mathrm{C}$. The volumes of MBs-peptide and $E$. coli were at the ratio of 1:5. After incubation, washing and separation with magnetic field, $5 \mu \mathrm{L}$ of the incubated MBs-peptide was dropped on the indicator electrodes for potentiometric measurements. Before measurements, the electrodes were conditioned in $1.0 \mathrm{mM}$ PBS containing $1.0 \mathrm{mM} \mathrm{NaCl}$ for $300 \mathrm{~s}$ to obtain a stable potentiometric response. Potential differences of MBs-peptide before and after incubation with $E$. coli were used for quantification of $E$. coli. 


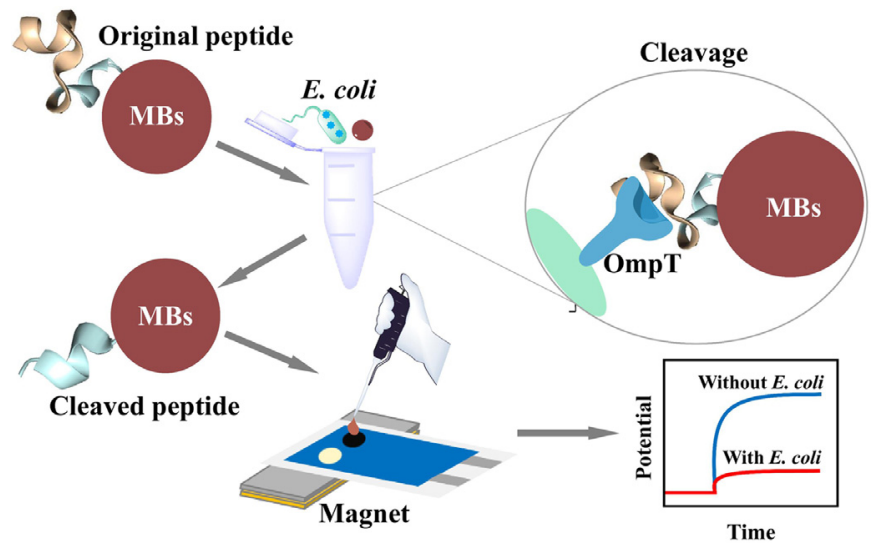

Scheme 1. Schematic illustration of the magneto-controlled potentiometric assay for $E$. coli sensing based on the cleavage of peptide on magnetic beads. MBs, streptavidin-modified magnetic beads.

\section{Results and discussion}

3.1. Mechanism of the magneto-controlled potentiometric assay for $\mathrm{E}$. coli detection

In order to achieve sensitive potentiometric measurements, the peptides that can be digested by OmpT were rationally designed. OmpT is known as a hydrolytic enzyme on the outer membrane of E. coli and can preferentially cleave peptide at dibasic sites (-R-R, -K-K-, -K-R-, and -R-K-). [23] The pyrolysis efficiency of OmpT is comparable to water-soluble proteases. If proline $(\mathrm{P})$ is located on the carboxyl side of the cleavage site, hydrolysis of the -R-P- will be weaker for protease such as trypsin. [26,29] Moreover, previous studies have shown that arginine $(\mathrm{R})$-rich protamine can induce a large and reproducible potential response on a polymeric membrane electrode doped with ion-exchanger. [27] Therefore, besides synthetic peptides with cleavage site (-R-R-) and different amounts of arginine (Table 1), a synthetic peptide with proline located on the carboxyl side of the cleavage site was also designed. To immobilize the peptide on the magnetic beads via biotin-streptavidin interactions, biotin was added to the N-terminal of the sequences. In addition, three glycine acted as a spacer to impart chain flexibility were also added.

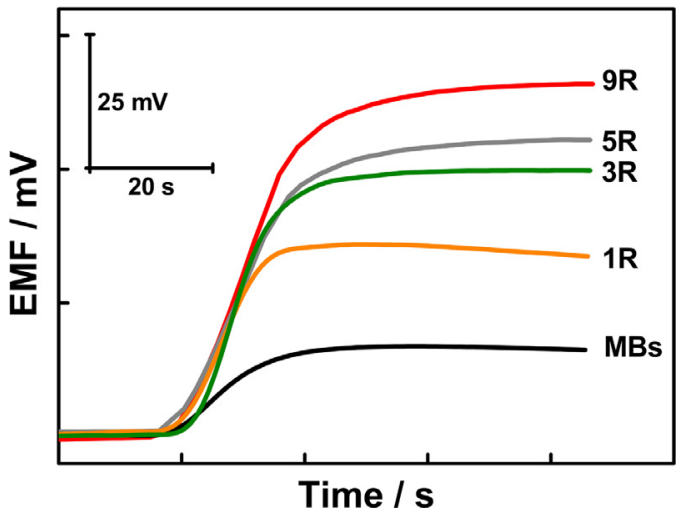

Fig. 1. Potentiometric response of ISE to $\mathrm{MBs}$ and $\mathrm{MBs}$-peptide in $1.0 \mathrm{~mL}$ PBS (1.0 mM pH 7.4) containing $1.0 \mathrm{mM} \mathrm{NaCl} .5 \mu \mathrm{L}$ of MBs and MBs-peptide (10 mg $\mathrm{mL}^{-1}$ ) was used. MBs, streptavidin-modified magnetic beads; $9 \mathrm{R}, 5 \mathrm{R}, 3 \mathrm{R}$, and $1 \mathrm{R}$ represent MBs modified with peptide-9R, peptide-5R, peptide-3R, and peptide- $1 R$ respectively. The arrow at $20 \mathrm{~s}$ represents the sample addition.

The sensing principle is illustrated in Scheme 1. External magnetic fields enhance the accumulation and extraction of hydrophilic peptide into the polymeric membrane via the formation of ion pairs with the ion exchanger (i.e., DNNS) in the membrane phase. As a result, phase boundary potential at the membrane sample/interface achieves a relatively significant and rapid change. In the presence of $E$. coli, OmpT on the surface of $E$. coli enables the cleavage of peptide at dibasic sites (-R-R-), which leads to a charge density change on the surface of MBs-peptide. Such changes of surface charge can be sensitively detected by polymeric membrane ion-sensitive sensors under magnetic field. The sensing protocol is label-free and can eliminate the procedure for bacteria lysis. Moreover, the peptide functionalized magnetic beads are capable of controlling the enzymatic hydrolysis process and subsequent potentiometric sensing.

Recently, we have shown that peptides immobilized on magnetic beads could be attached to or even extracted into polymeric membrane and lead to a rapid potential response in the presence of magnetic field. [20] To further investigate the magnetocontrolled potentiometric sensing mechanism, it would be ideal to design peptides with the precise amino acids and charge density (Table 1). As shown in Fig. 1, peptide-modified MBs can lead to

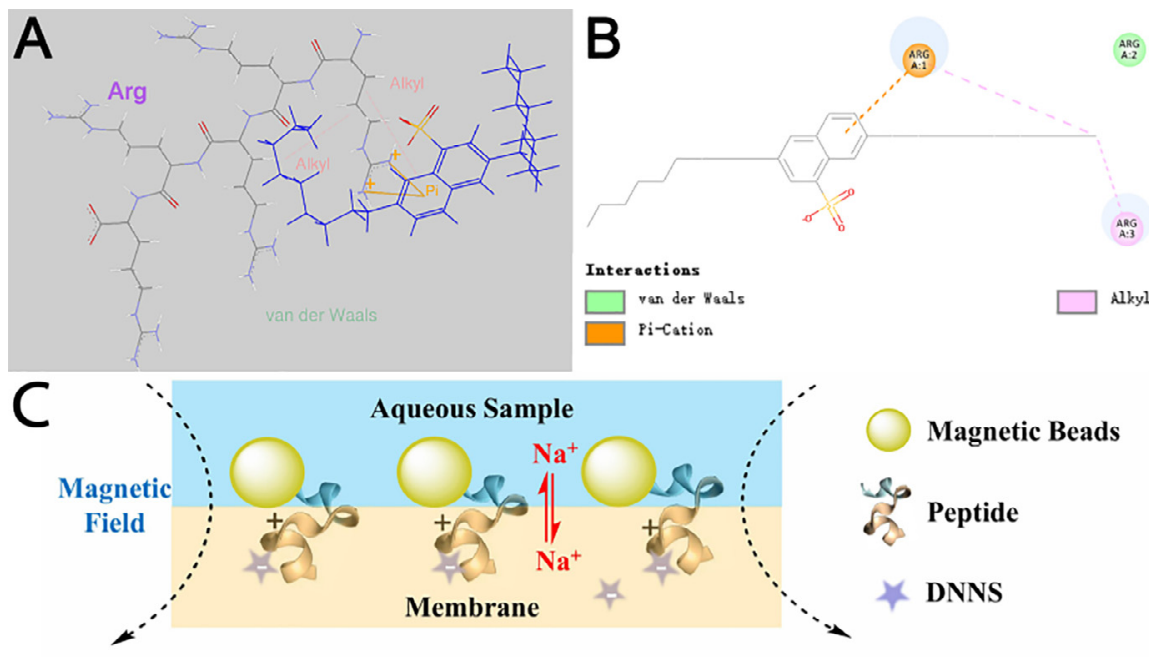

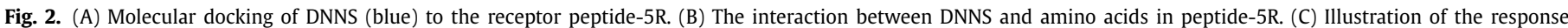

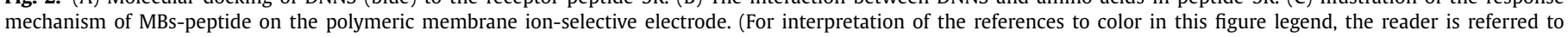
the web version of this article.) 


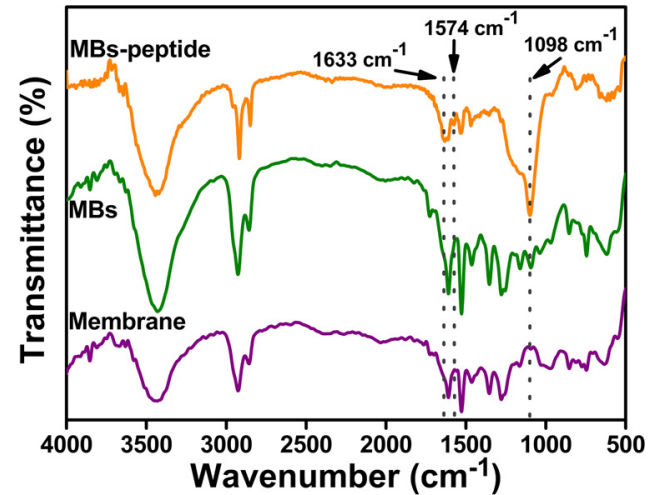

Fig. 3. FTIR spectra of bare membrane (purple), membrane dropped with MBs (green) and membrane dropped with MBs-peptide-9R (orange) under magnetic force. Membranes dropped with MBs and MBs-peptide-9R were washed with freshly deionized water and dried before characterization. (For interpretation of the references to color in this figure legend, the reader is referred to the web version of this article.)

a rapid, stable and reproducible potential response on the polymeric membrane ion-sensitive sensor. More importantly, with the amount of arginine in peptide increasing, the potentiometric responses of the electrode increase.

Molecular docking analysis reveals that the arginine in peptide can interact with the ion exchanger DNNS via van der Waals force, $\pi$-cation, and alkyl interactions (Fig. 2A, B). Moreover, the binding strength to DNNS can enhance with increasing the amount of arginine in the peptide (Related interaction forces and CDOCKER interaction energy are listed in Table S1). Therefore, peptides with higher charge density are more favorably extracted into the polymeric membrane to induce the ion exchange between the peptide in the sample solution and sodium ions in the membrane. The ion exchange process results in the potentiometric response (Fig. 2C). This is analogous to polymeric membrane-based potentiometric polyion sensors where the potential response is dependent on both the charge density and molecular weight. [30] However, a potential difference of ca. $38 \mathrm{mV}$ was observed for the present system when measuring the same amount of MBs-peptide in $1.0 \mathrm{mM}$ PBS containing 1.0 and $10 \mathrm{mM} \mathrm{NaCl}$, respectively (Fig. S2). The potential difference is smaller than that predicted by the equilibrium potential response model (a Nernstain potential response for $\mathrm{Na}^{+}$). This is probably due to the high hydrophilicity of the peptide and the relatively weak interaction between the peptide and DNNS in the membrane phase. [20]

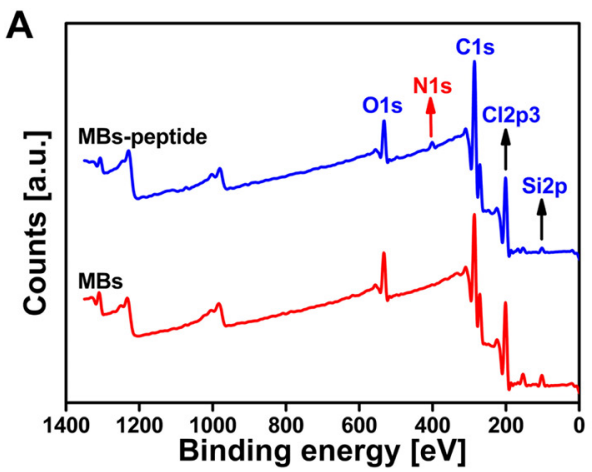

\subsection{Confirmation of the ion-pair formation in membrane}

As discussed in our previous communication, ion-pair formation between peptide on the MBs and ion exchanger within the polymer membranes leads to the potentiometric responses. [20] In order to verify this hypothesis, the infrared spectra of the membrane without and with addition of MBs-peptide under magnetic force were recorded. After dropping with MBs-peptide, strong washing with freshly deionized water and drying, the membrane shows three peaks at $1098 \mathrm{~cm}^{-1}$ (C-O stretching), $1633 \mathrm{~cm}^{-1} \quad(\mathrm{C}=\mathrm{N}$ stretching) and $1574 \mathrm{~cm}^{-1}(\mathrm{C}=\mathrm{N}$ bending). These peaks are characteristics of arginine in peptide, but were not obvious in the spectrum of the bare membrane and membrane dropped with MBs (Fig. 3). [31] Therefore, the lipophilic cation exchanger within the membrane phase can likely interact with the arginine in the peptide and leads to the accumulation and even extraction of the MBspeptide into the polymeric membrane.

Extraction of peptide into the polymeric membrane were also characterized by X-ray photoelectron spectroscopy (XPS). Nitrogen $1 \mathrm{~s}$ peak centered at $400.2 \mathrm{eV}$ is often assigned as amide bonds (-CO-NH-) (Fig. 4). [32] The appearance of -CO-NH- component in arginine of peptide indicates the extraction of the peptide into membrane. Besides, field-emission scanning electron microscopy (FE-SEM) also shows that MBs-peptide can be adsorbed on the membrane (Fig. S3). All these results above indicate that peptide on the MBs at least partially can be extracted into the polymeric membrane in the presence of ion exchanger and magnetic force.

\subsection{Optimization for potentiometric measurement of MBs-peptide}

According to our previous research, the membrane containing PVC and 0 -NPOE in a weight ratio of $1: 1,1 \mathrm{wt} \%$ DNNS and $1 \mathrm{wt} \%$ ETH 500 was used for further experiments. [20] In order to increase the total electromotive force (EMF) response, experimental conditions including the magnetic field intensity, amount of MBspeptide, and background solution were optimized. The potential difference between MBs-peptide and MBs was used for optimization. Magnetic field was controlled by the number of magnets. Since the layer thicknesses of aqueous diffusion could be modulated by the magnetic field, with the number of magnets increasing, potential change will increase (Fig. 5A). Then, it will decrease, which is due to the reduced ion-exchange process. The EMF response of the electrode to different amounts of MBs-peptide was investigated. As shown in Fig. 5B, potential difference decreased when the amount of MBs-peptide exceeds $5 \mu \mathrm{L}$ because of the high background signal originated from the extraction of the MBs. Therefore, $5 \mu \mathrm{L}$ MBs-peptide was used in this study. Moreover, a low background electrolyte (1.0 mM PBS, pH 7.4 containing $1.0 \mathrm{mM}$ $\mathrm{NaCl}$ ) was used to obtain a sensitive EMF response (Fig. S2).

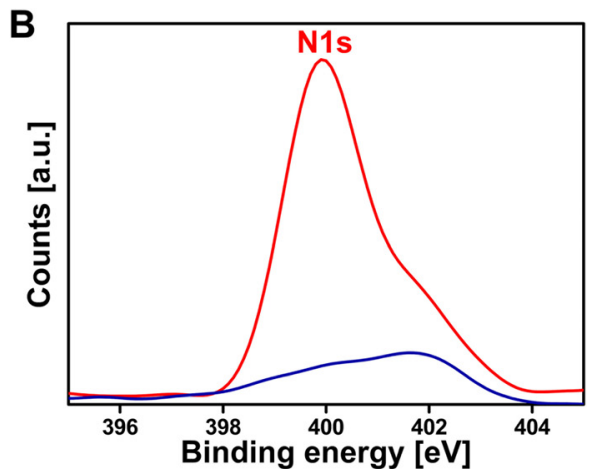

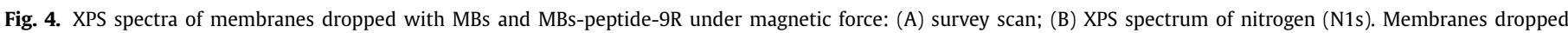
with MBs and MBs-peptide-9R were washed with freshly deionized water and dried before characterization. 

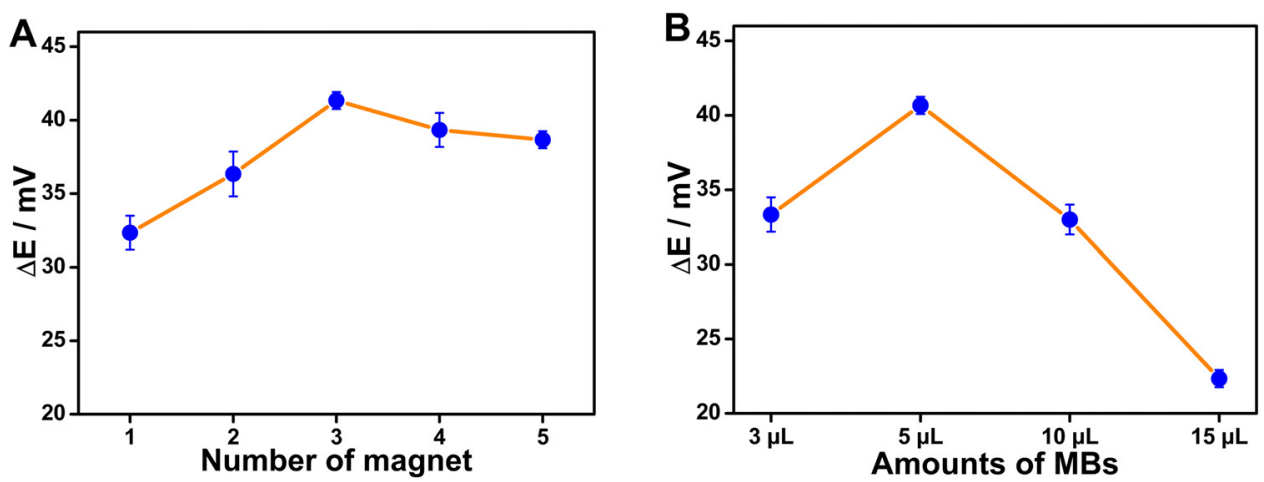

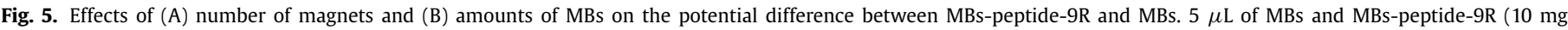
$\mathrm{mL}^{-1}$ ) were used. The potential difference between MBs-peptide and MBs was used for optimization. Error bars represent one standard deviation for three measurements.
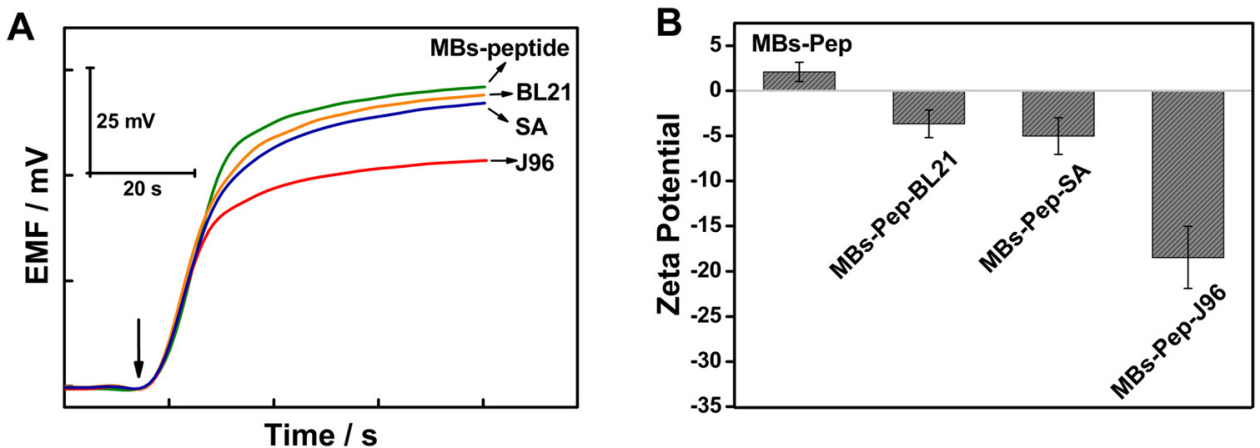

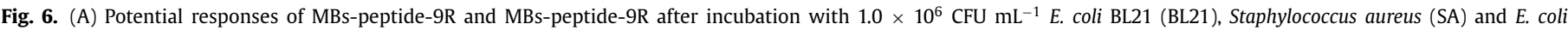

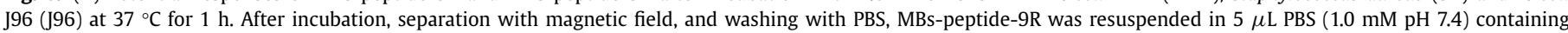

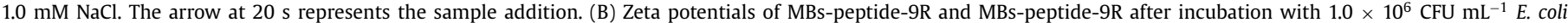
BL21, SA and E. coli J96. Error bars represent one standard deviation for three measurements.
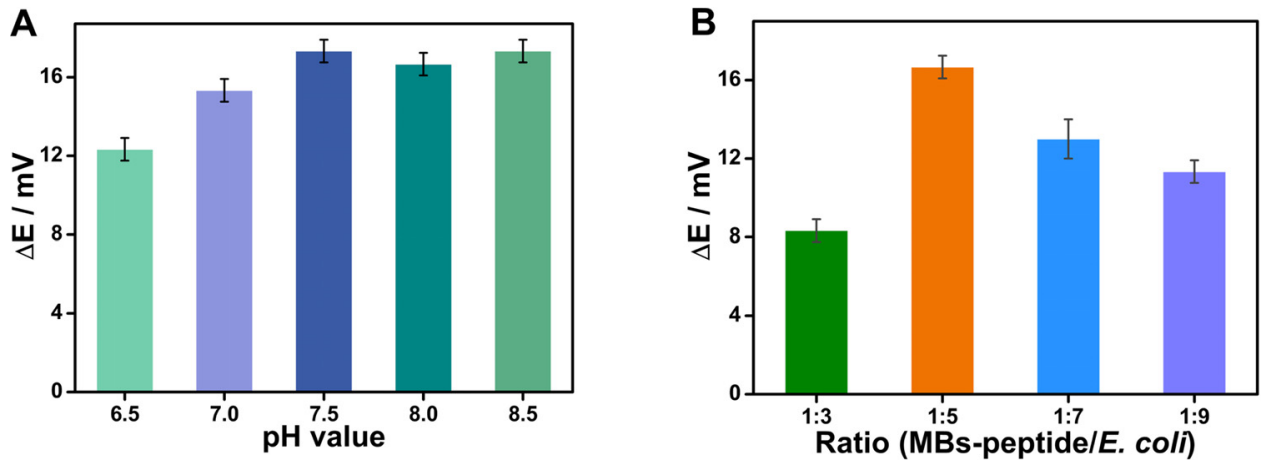

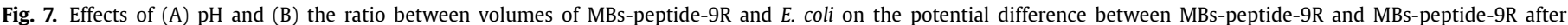

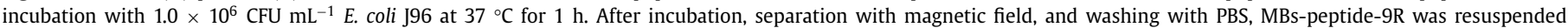

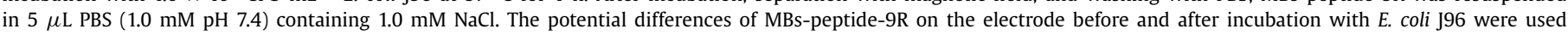
to evaluate the cleavage efficiencies of OmpT. Error bars represent one standard deviation for three measurements.

\subsection{Evaluation of enzyme digestion}

OmpT is on the surface of all wild-type E. coli strains. [33] The pyrolysis efficiency of OmpT is known to comparable to trypsin. [26] Our preliminary experiments have shown that the peptide on the magnetic beads can be digested in the presence of trypsin (Fig. S4). In this study, a strain of wild-type E. coli (E. coli J96) expressing OmpT at a high level was selected as a model. E. coli BL21 lacks of the genes necessary to synthesize OmpT on its surface was used as a negative control. [33] To improve the sensitivity of the potentiometric assay, peptide-PR was initially designed as a substrate. However, compared with the potential change of MBs-peptide-9R on the electrode before and after digestion by OmpT, much lower potential change of MBs-peptide-PR was observed (Fig. S5). Therefore, peptide-9R was selected for further experiments. As shown in Fig. 6A, the potential change of MBs-peptide-9R on the electrode was obvious $(16 \mathrm{mV})$ after incubation with $1.0 \times 10^{6} \mathrm{CFU} \mathrm{\textrm {mL } ^ { - 1 }} \mathrm{E}$. coli J96. However, for the control strains such as E. coli BL21 and Staphylococcus aureus ( $S$. aureus), a potential change of $3 \mathrm{mV}$ was observed, which indicates that the OmpT plays a key role in the cleavage of peptide on the magnetic beads. The background potential change is probably due to the nonspecific interaction of the negatively charged bacteria.

Since the zeta potential analyzer can be used to conveniently measure the surface charge change, zeta potentials of MBs-peptide and MBs-peptide after incubation with E. coli $\mathrm{J} 96$ and control 
Table 2

Comparison of several enzyme-based techniques for $E$. coli detection.

\begin{tabular}{lllll}
\hline Enzyme & Methods & LOD $($ CFU mL & Assay Time $(\mathrm{h})$ & Ref. \\
\hline$\beta$-Galactosidase & Colorimetry & $10^{4}$ & 2.5 & 34 \\
$\beta$-Galactosidase & Luminescence & 40 & 8 & 35 \\
$\beta$-D-Galactosidase & Amperometry & $10^{5}$ & 1 & 36 \\
$\beta$-D-Glucuronidase & Fluorometry & $10^{5}$ & 2 & 37 \\
$\beta$-D-Glucuronidase & Amperometry & $5 \times 10^{4}$ & 3 & 38 \\
OmpT $^{\text {a }}$ & Fluorometry & $10^{5}$ & 1 & 33 \\
OmpT & Potentiometry & $5 \times 10^{3}$ & 1 & This work \\
\hline
\end{tabular}

a OmpT, outer-membrane protease $\mathrm{T}$.

strains (E. coli BL21 and S. aureus) were also investigated. As shown in Fig. 6B, zeta potential value of the MBs-peptide-9R changes from the initial positive value $(2.09 \pm 1.07 \mathrm{mV})$ to a negative value (e.g., $-18.47 \pm 3.42 \mathrm{mV}$ in the presence of $1.0 \times 10^{6} \mathrm{CFU} \mathrm{mL}{ }^{-1} \mathrm{E}$. coli J96), which indicates the cleavage of peptide on magnetic beads. In contrast, nonspecific interaction of the control strains can only leads to a zeta potential decrease of ca. $5 \mathrm{mV}$. These results revealed the feasibility and selectivity for E. coli J96 sensing with peptide-9R modified magnetic beads.

\subsection{Potentiometric detection of $\mathrm{E}$. coli}

In order to achieve sensitive potentiometric measurements, experimental parameters including $\mathrm{pH}$ and ratio between MBspeptide-9R and E. coli were optimized. As shown in Fig. 7A, the cleavage efficiencies of OmpT improved with increasing $\mathrm{pH}$ values (from 6.5 to 8.5), and the maximum efficiency of OmpT was achieved at $\mathrm{pH}$ 7.5. This result is roughly consistent with a previous report. [25] Experiments also show that the maximum cleavage efficiency of OmpT was obtained by incubating MBs-peptide-9R with E. coli $\mathrm{J} 96\left(10^{6} \mathrm{CFU} \mathrm{mL}^{-1}\right)$ at a ratio of $1: 5$ (Fig. 7B). Moreover, as a counterbalance of sensitivity and detection time, the incubation time of $1 \mathrm{~h}$ was used.

The proposed potentiometric E. coli assay was measured based on the surface charge change on the MBs-peptide. Therefore, the surface charge change of MBs-peptide can be quantified by the zeta potentials and be used for the E. coli detection. As shown in Fig. 8A, in the presence of $E$. coli J96, the surface positive charge of MBs-peptide-9R decreased, resulting in the decrease of zeta potential of MBs-peptide-9R. More importantly, as E. coli J96 concentration increases from $1.0 \times 10^{4}$ to $1.0 \times 10^{7} \mathrm{CFU} \mathrm{mL} \mathrm{m}^{-1}$, an increase in zeta potential change (from $-0.92 \pm 0.40 \mathrm{mV}$ to $-28.50 \pm 2.12 \mathrm{mV}$ ) was observed. Indeed, by increasing the concentration of $E$. coli $\mathrm{J} 96$ cells, more peptides on the magnetic beads can be digested and thus reduce the surface charge or charge density, resulting in the steadily decrease of the potential response of the MBs-peptide-9R on the electrode. A linear relationship between the potential change and logarithmic value of $E$. coli J96 concentrations was found ranging from $5.0 \times 10^{3}$ to $1.0 \times 10^{7}$

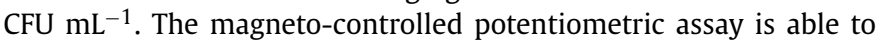
detect the E. coli $\mathrm{J} 96$ at concentrations down to $5.0 \times 10^{3} \mathrm{CFU}$ $\mathrm{mL}^{-1}$ (Fig. 8B, C). The detection limit of several similar techniques for $E$. coli strains are summarized and compared in Table 2. The proposed system is comparable with or even better than other enzyme-based assays. [33-38] More importantly, peptide functionalized magnetic beads offer the benefits of simplicity, speed, stable and flexibility to perform potentiometric detection based on surface charge change. The detection time is shorter than most commercially available detection kits for E. coli. $[33,34,37,38]$ Note that, by prolonging the incubation time and using a pre-culture step, $[33,39]$ the limit of detection can be further improved to satisfy the World Health Organization standard for E. coli content in drinking water. Since some other bacteria including Shigella flexneri, Salmonella enterica and Yersinia pestis can also express sim-
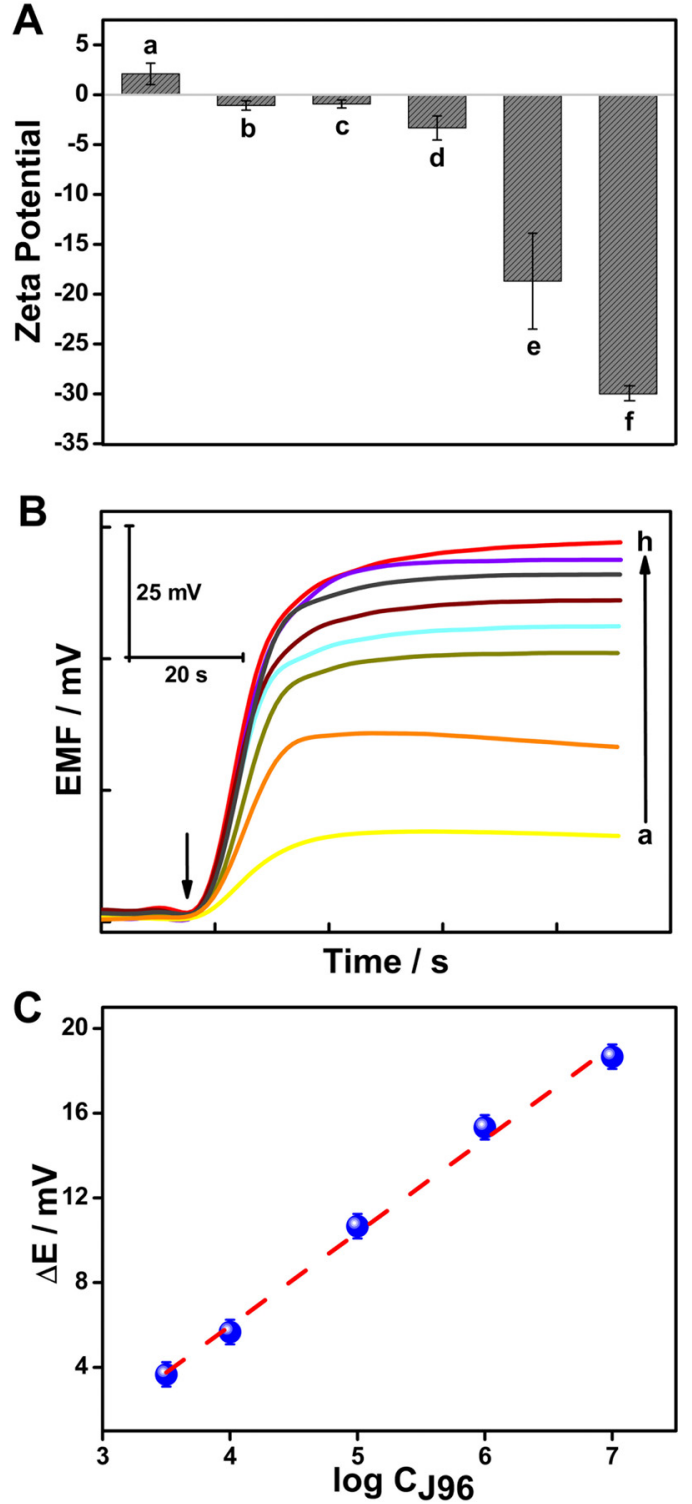

Fig. 8. (A) Zeta potentials of (a) MBs-peptide-9R and MBs-peptide-9R after incubation with (b) $1.0 \times 10^{3}$; (c) $1.0 \times 10^{4}$; (d) $1.0 \times 10^{5}$; (e) $1.0 \times 10^{6}$; (f) $1.0 \times 10^{7}$ $\mathrm{CFU} \mathrm{mL} \mathrm{m}^{-1}$ E. coli $\mathrm{J} 96$ at $37{ }^{\circ} \mathrm{C}$ for $1 \mathrm{~h}$. After incubation, separation with magnetic field, and washing with PBS, MBs-peptide-9R was resuspended in $500 \mu \mathrm{L}$ PBS $(1.0 \mathrm{mM}$ pH 7.4) containing $1.0 \mathrm{mM} \mathrm{NaCl}$. (B) The potentiometric response of (a) MBs; (b) MBs-peptide-1R and MBs-peptide-9R after incubation with (c) $1.0 \times 10^{7}$; (d) $1.0 \times 10^{6}$; (e) $1.0 \times 10^{5}$; (f) $1.0 \times 10^{4}$; (g) $5.0 \times 10^{3}$; (h) 0 CFU mL ${ }^{-1}$ E. coli J96. The arrow at $20 \mathrm{~s}$ represents the sample addition. (C) Potential changes of MBspeptide-9R after incubation with E. coli J96 at concentrations range of $5.0 \times 10^{3}-$ $1.0 \times 10^{7} \mathrm{CFU} \mathrm{mL} \mathrm{mL}^{-1}$. Error bars represent one standard deviation for three measurements. 
ilar outer-membrane proteases, [40] the proposed method can be used to detect multiple bacteria by designing peptides with different cleavage sites. Compared to a number of serine proteases and metalloproteases, OmpT exhibits a remarkable tolerance of lysine/arginine methylation and acetylation. [25] Moreover, previous reports have shown that by changing the residues of the nearestneighbor positions at the cleavage site, the catalytic efficiency of OmpT can be significantly improved. [41] Therefore, the substrate specificity of the OmpT might be further enhanced by changing the residue types or using methylated arginine.

To further investigate the feasibility of the magneto-controlled potentiometric assay for direct detection of $E$. coli cells in real samples, coastal seawater samples and standard seawater spiked with $1.0 \times 10^{6} \mathrm{CFU} \mathrm{mL}{ }^{-1}$ E. coli J96 suspensions were tested. Compared to the standard samples $\left(1.0 \times 10^{6} \mathrm{CFU} \mathrm{mL}{ }^{-1}\right.$ E. coli J96 in PBS), a potential change decrease of $4 \mathrm{mV}$ for standard seawater samples and $6 \mathrm{mV}$ for coastal seawater samples were observed (data are not shown here). Some negatively charged species including anionic surfactants, negative charged biomolecules or organisms in real samples may electrostatically interact with positively-charged peptide and lead to the background signal. While both the sample matrix and interferences presented in sample may affect the performance of the assay, [23] the interferences can be eliminated by using a filtration system that facilitates separation and preconcentration of the target organism as described in our previous research. [39]

\section{Conclusions}

In conclusion, a magneto-controlled potentiometric assay for $E$. coli $\mathrm{J} 96$ based on outer-membrane protease T (OmpT) have been developed. We demonstrated the feasibility of utilizing a magnetic force for the extraction of the peptide into an ion-exchangerbased polymeric membrane. The magnetic-field-assisted accumulation and extraction of the peptide into the membrane can induce an electromotive force response in a similar way to the polyion sensor. By making use of the OmpT on the surface of E. coli and the specific cleavage of peptide at the center of two pairs of arginine, E. coli can be detected accurately without any amplification or enrichment in $5000 \mathrm{CFU} \mathrm{\textrm {mL } ^ { - 1 }}$ level with high selectivity. Owing to the simplicity, flexibility and versatility of the peptide functionalized magnetic beads, we envision that the magneto-controlled potentiometric assay holds great potential for rapid, sensitive and selective bacteria analysis.

\section{Declaration of Competing Interest}

The authors declare that they have no known competing financial interests or personal relationships that could have appeared to influence the work reported in this paper.

\section{Credit authorship contribution statement}

Han Zhang: Methodology, Investigation, Data curtion, Writing - original draft. Junsong Mou: Methodology, Software. Jiawang Ding: Conceptualization, Writing - review \& editing, Supervision, Funding acquisition. Wei Qin: Supervision, Funding acquisition, Project administration.

\section{Acknowledgment}

This work was supported by the National Natural Science Foundation of China (41876108 and U2006208); the Instrument Developing Project of the Chinese Academy of Sciences (Y728021021); the Taishan Scholar Program of Shandong Province (tspd20181215, tsqn201909163); and Key Research and Development Program of Yantai (2018ZHGY053).

\section{Supplementary materials}

Supplementary material associated with this article can be found, in the online version, at doi:10.1016/j.electacta.2021.138408.

\section{References}

[1] J. Vila, E. Saez-Lopez, J.R. Johnson, U. Romling, U. Dobrindt, R. Canton, C.G. Giske, T. Naas, A. Carattoli, M. Martinez-Medina, J. Bosch, P. Retamar, J. Rodriguez-Bano, F. Baquero, S.M. Soto, Escherichia coli: an old friend with new tidings, FEMS Microbiol. Rev, 40 (2016) 437.

[2] Y.A. Pachepsky, D.R. Shelton, Escherichia coli and fecal coliforms in freshwater and estuarine sediments, Crit. Rev. Environ. Sci. Technol. 41 (2011) 1067.

[3] F. Carvalho, J. George, H.M.A. Sheikh, R. Selvin, Advances in screening, detection and enumeration of Escherichia coli using nanotechnology-based methods: a review, J. Biomed. Nanotechnol. 14 (2018) 829.

[4] R. Bain, R. Cronk, R. Hossain, S. Bonjour, K. Onda, J. Wright, H. Yang, T. Slaymaker, P. Hunter, A. Pruss-Ustun, J. Bartram, Global assessment of exposure to faecal contamination through drinking water based on a systematic review, Trop. Med. Int. Health 19 (2014) 917.

[5] R.M. Carr, U.J. Blumenthal, D.D. Mara, Guidelines for the safe use of wastewater in agriculture: revisiting WHO guidelines, Water Sci. Technol. 50 (2004) 31.

[6] T. Bigham, J.S.G. Dooley, N.G. Ternan, W.J. Snelling, M.C. Héctor Castelán, J. Davis, Assessing microbial water quality: electroanalytical approaches to the detection of coliforms, TrAC, Trends Anal. Chem. 121 (2019) 115670

[7] X. Lv, Y.M. Huang, D.F. Liu, C.W. Liu, S. Shan, G.Q. Li, M.L. Duan, W.H. Lai, Multicolor and ultrasensitive enzyme-linked immunosorbent assay based on the fluorescence hybrid chain reaction for simultaneous detection of pathogens, J. Agric. Food Chem. 67 (2019) 9390.

[8] M.C. Deng, Y. Wang, L. Jia, N-Methylimidazolium modified magnetic particles-assisted highly sensitive Escherichia coli detection based on polymerase chain reaction and capillary electrophoresis, Anal. Chim. Acta 827 (2014) 47.

[9] S.B. He, X.Y. Hong, M.M. Zhang, L.N. Wu, X.M. Yan, Label-free detection of bacteria in fruit juice by nano-flow cytometry, Anal. Chem. 92 (2020) 2393.

[10] X.S. Jiang, R.H. Wang, Y. Wang, X.L. Su, Y.B. Ying, J.P. Wang, Y.B. Li, Evaluation of different micro/nanobeads used as amplifiers in QCM immunosensor for more sensitive detection of E. coli 0157:H7, Biosens. Bioelectron. 29 (2011) 23.

[11] H. Kaur, M. Shorie, P. Sabherwal, Electrochemical aptasensor using boroncarbon nanorods decorated by nickel nanoparticles for detection of E. coli O157:H7, Microchim. Acta 187 (2020) 461

[12] E. Bakker, P. Bühlmann, E. Pretsch, Carrier-based ion-selective electrodes and bulk optodes. 1. General characteristics, Chem. Rev. 97 (1997) 3083.

[13] J. Bobacka, A. Ivaska, A. Lewenstam, Potentiometric ion sensors, Chem. Rev. 108 (2008) 329.

[14] S. Papp, G. Jagerszki, R.E. Gyurcsányi, Ion-selective electrodes based on hydrophilic ionophore-modified nanopores, Angew. Chem. Int. Ed. 57 (2018) 4752.

[15] E. Zdrachek, E. Bakker, Potentiometric sensing, Anal. Chem. 93 (2021) 72

[16] J.W. Ding, B.W. Li, L.X. Chen, W. Qin, A three-dimensional origami paper-based device for potentiometric biosensing, Angew. Chem. Int. Ed. 55 (2016) 13033.

[17] J.W. Ding, W. Qin, Recent advances in potentiometric biosensors, TrAC, Trends Anal. Chem. 124 (2020) 115803

[18] A. Karimzadeh, M. Hasanzadeh, N. Shadjou, M. de la Guardia, Peptide based biosensors, TrAC, Trends Anal. Chem. 107 (2018) 1.

[19] E.G. Lv, J.W. Ding, W. Qin, Potentiometric detection of Listeria monocytogenes via a short antimicrobial peptide pair-based sandwich assay, Anal. Chem. 90 (2018) 13600.

[20] E.G. Lv, Y.H. Li, J.W. Ding, W. Qin, Magnetic field-driven extraction of bioreceptors into polymeric membranes for label-free potentiometric biosensing, Angew. Chem. Int. Ed. 60 (2021) 2609.

[21] B. Fu, E. Bakker, J.H. Yun, V.C. Yang, M.E. Meyerhoff, Response mechanism of polymer membrane-based potentiometric polyion sensors, Anal. Chem. 66 (1994) 2250

[22] A. Ebbensgaard, H. Mordhorst, F.M. Aarestrup, E.B. Hansen, The role of outer membrane proteins and lipopolysaccharides for the sensitivity of Escherichia coli antimicrobial peptides, Front. Microbiol. 9 (2018) 2153.

[23] C.H. Yam, W.Y. Siu, D. Kaganovich, J.V. Ruderman, R.Y.C. Poon, Cleavage of cyclin A at R70/R71 by the bacterial protease OmpT, Proc. Natl. Acad. Sci. U. S. A. 98 (2001) 497.

[24] N. Dekker, R.C. Cox, R.A. Kramer, M.R. Egmond, Substrate specificity of the integral membrane protease OmpT determined by spatially addressed peptide libraries, Biochemistry 40 (2001) 1694.

[25] Y.J. Hu, L. Zhang, J.J. Chen, J. Yao, H. Jin, P.Y. Yang, Outer membrane protease OmpT-based strategy for simplified analysis of histone post-translational modifications by mass spectrometry, Anal. Chem. 92 (2020) 732.

[26] R.A. Kramer, D. Zandwijken, M.R. Egmond, N. Dekker, In vitro folding, purification and characterization of Escherichia coli outer membrane protease OmpT, Eur. J. Biochem. 267 (2000) 885.

[27] N. Ramamurthy, N. Baliga, J.A. Wahr, U. Schaller, V.C. Yang, M.E. Meyerhoff, Improved protamine-sensitive membrane electrode for monitoring heparin concentrations in whole blood via protamine titration, Clin Chem 44 (1998) 606.

[28] J.W. Ding, Y. Gu, F. Li, H.X. Zhang, W. Qin, DNA nanostructure-based magnetic beads for potentiometric aptasensing, Anal. Chem. 87 (2015) 6465.

[29] J. Rodriguez, N. Gupta, R.D. Smith, P.A. Pevzner, Does trypsin cut before proline? J. Proteome Res. 7 (2008) 300. 
[30] S.C. Ma, V.C. Yang, M.E. Meyerhoff, Heparin-responsive electrochemical sensor: a preliminary study, Anal. Chem. 64 (1992) 694.

[31] P. Jain, K. Patel, A.K. Jangid, A. Guleria, S. Patel, D. Pooja, H. Kulhari, Modulating the delivery of 5-fluorouracil to human colon cancer cells using multifunctional arginine-coated manganese oxide nanocuboids with MRI properties, ACS Appl. Bio Mater. 3 (2020) 6852

[32] Y.O. Zhang, N.V. Hudson-Smith, S.D. Frand, M.S. Cahill, L.S. Davis, Z.V. Feng C.L. Haynes, R.J. Hamers, Influence of the spatial distribution of cationic functional groups at nanoparticle surfaces on bacterial viability and membrane interactions, J. Am. Chem. Soc. 142 (2020) 10814.

[33] G. Sinsinbar, S. Gudlur, S.E. Wood, G. Ammanath, H.U. Yildiz, P. Alagappan, M. Mrksich, B. Liedberg, Outer-membrane protease (OmpT) based E. coli sensing with anionic polythiophene and unlabeled peptide substrate, Angew. Chem. Int. Ed. 59 (2020) 18068.

[34] J.H. Chen, S.D. Alcaine, Z.W. Jiang, V.M. Rotello, S.R. Nugen, Detection of Escherichia coli in drinking water using $\mathrm{T} 7$ bacteriophage-conjugated magnetic probe, Anal. Chem. 87 (2015) 8977.

[35] S. Burnham, J. Hu, H. Anany, L. Brovko, F. Deiss, R. Derda, M.W. Griffiths, Towards rapid on-site phage-mediated detection of generic Escherichia coli in water using luminescent and visual readout, Anal. Bioanal. Chem. 406 (2014) 5685 .
[36] S. Noh, Y. Choe, V. Tamilavan, M.H. Hyun, H.Y. Kang, H. Yang, Facile electrochemical detection of Escherichia coli using redox cycling of the product generated by the intracellular beta-D-galactosidase, Sens. Actuators, B 209 (2015) 951.

[37] S. Barizuddin, B. Balakrishnan, R.C. Stringer, M. Dweik, Highly specific and rapid immuno-fluorescent visualization and detection of E. coli 0104:H4 with protein-A coated magnetic beads based LST-MUG assay, J. Microbiol. Methods 115 (2015) 27.

[38] M. Rochelet, S. Solanas, L. Betelli, B. Chantemesse, F. Vienney, A. Hartmann, Rapid amperometric detection of Escherichia coli in wastewater by measuring beta-D glucuronidase activity with disposable carbon sensors, Anal. Chim. Acta 892 (2015) 160.

[39] J.W. Ding, J.H. Lei, X. Ma, J. Gong, W. Qin, Potentiometric aptasensing of Listeria monocytogenes using protamine as an indicator, Anal. Chem. 86 (2014) 9412.

[40] V. Hritonenko, C. Stathopoulos, Omptin proteins: an expanding family of outer membrane proteases in Gram-negative Enterobacteriaceae, Mol. Membr. Biol. 24 (2007) 395.

[41] S.E. Wood, G. Sinsinbar, S. Gudlur, M. Nallani, C.F. Huang, B. Liedberg, M. Mrksich, A bottom-up proteomic approach to identify substrate specificity of outer-membrane protease OmpT, Angew. Chem. Int. Ed. 56 (2017) 16531. 